PREVENTIF: JURNAL KESEHATAN MASYARAKAT

FAKULTAS KESEHATAN MASYARAKAT, UNIVERSITAS TADULAKO

http://jurnal.fkm.untad.ac.id/index.php/preventif

\title{
Pengaruh Peran Pengawas Menelan Obat dan Efek Samping Obat Anti Tuberkulosis Terhadap Angka Kesembuhan (Cure Rate) Pasien Tuberkulosis
}

\author{
Fauziah Amining ${ }^{1}$, Herawanto $^{*^{2}}$, Dilla Srikandi Syahadat ${ }^{2}$, Hasanah $^{3}$ \\ ${ }^{1}$ Departemen Histologi, Fakultas Kedokteran, Universitas Tadulako \\ ${ }^{2}$ Departemen Epidemiologi, Fakultas Kesehatan Masyarakat, Universitas Tadulako \\ ${ }^{3}$ Program Studi Kesehatan Masyarakat, Fakultas Kesehatan Masyarakat, Universitas \\ Tadulako
}

Author's Email Correspondence (*) herawanto@untad.ac.id

(08114500469)

\begin{abstract}
ABSTRAK
Kunci sukses penanggulangan TBC adalah penemuan pasien dan pengobatan pasien sampai sembuh. keberhasilan pengobatan dipengaruhi oleh beberapa faktor yaitu faktor kepatuhan pasien, faktor pengawas menelan obat dan efek samping yang dirasakan pasien. Kecamatan Palu Selatan merupakan penyumbang angka kejadian TBC yang cukup tinggi dengan angka kesembuhan pasien TBC yang belum mencapai target nasional (85\%). Wilayah Kecamatan Palu Selatan terdiri dari 3 Puskesmas yaitu Puskesmas Mabelopura terdapat 62 kasus, Puskesmas Birobuli 46 kasus dan Puskesmas Bulili 28 kasus, dengan angka kesembuhan yaitu Puskesmas Mabelopura 44 (70,96\%) kasus, Puskesmas Birobuli 30 $(65,21 \%)$ kasus dan Puskesmas Bulili 19 (67,85\%) kasus. Penelitian ini bertujuan untuk mengetahui faktor yang mempengaruhi angka kesembuhan TBC di Kecamatan Palu Selatan. Jenis penelitian ini adalah kuantitatif dengan pendekatan cross sectional. Populasi berjumlah 136 orang dan sampel sebanyak 97 orang. Pengambilan sampel menggunakan teknik Proportionate Stratified Random Sampling. Analisis yang digunakan yaitu regresi linear sederhana dengan nilai $\alpha=5 \%$. Hasil penelitian ini menunjukkan bahwa ada pengaruh signifikan antara pengawas menelan obat (Sig. 0,010) dan efek samping (Sig. 0,010) terhadap angka kesembuhan pasien TBC. Disarankan kepada pasien TBC untuk patuh dalam mengonsumsi obat walaupun responden merasakan efek samping yang ditimbulkan oleh OAT, kepada keluarga diharapkan berperan aktif dalam mengawasi saat minum obat dan memberikan dukungan kepada pasien agar menyelesaikan pengobatan.
\end{abstract}

Kata Kunci: TBC, PMO, Efek Samping, Angka Kesembuhan 
Phone: +628114120202

Email: Preventif.fkmuntad@gmail.com

\begin{abstract}
The key to a successful TB control is patient discovery and treatment of the patient until healed. The success of treatment is influenced by several factors, namely patient adherence factors, factors controlling drug ingestion and side effects felt by the patient. Palu Selatan District is a contributor to the TB incidence rate which is quite high with the cure rate for TB patients who have not reached the national target (85\%). The area of South Palu District consists of 3 Puskesmas, namely Mabelopura Puskesmas with 62 cases, Puskesmas Birobuli 46 cases and Puskesmas Bulili 28 cases, with a cure rate namely Mabelopura Puskesmas 44 (70.96\%) cases, Puskesmas Birobuli 30 (65.21\%) cases and Puskesmas Bulili 19 (67.85\%) cases. This study aims to determine the factors that affect the TB cure rate in South Palu District. This type of research is quantitative with a cross sectional approach. The population numbered 136 people, after using the Lemeshow formula obtained a sample of 97 people. Sampling using the Proportionate Stratified Random Sampling technique. The analysis used is simple linear regression with a value of $\alpha=5 \%$. The results of this study indicate that there is a significant influence between supervisors ingesting drugs (Sig values of 0.010) and side effects (Sig values of $0.000)$ to the cure rate for TB patients. It is advisable for TB patients to obey in taking the drug even though the respondent feels the side effects caused by OAT, the family and health workers are expected to play an active role in supervising and providing support to patients to complete treatment and be declared cured
\end{abstract}

Keywords: TB, PMO, Side Effects, Cure Rate

\title{
PENDAHULUAN
}

Derajat kesehatan merupakan salah satu indikator kemajuan suatu masyarakat diantaranya adalah tingkat ekonomi, pendidikan, keadaan lingkungan, kesehatan dan sosial budaya. Salah satu sasaran nasional Rencana Pembangunan Jangka Menengah Nasional (RPJMN) yang tertuang pada Peraturan Presiden Nomor 59 Tahun 2017 tentang Sustainable Development Goals (SDGs) menetapkan target prevalensi Tuberkulosis (TBC) pada tahun 2019 menjadi 245 per 100.000 penduduk (1).

Tuberkulosis paru adalah penyakit menular langsung yang disebabkan oleh kuman Mycobacterium tuberculosis. Bakteri tersebut menyerang parenkim (jaringan) paru. TBC menular melalui percikan dahak yang mengandung kuman TBC kemudian bercampur dengan 
udara dan masuk ke dalam saluran pernafasan dan menginfeksi paru-paru. TBC paru dibagi menjadi 2 berdasarkan pemeriksaan dahak, yaitu TBC paru BTA positif dan TBC paru BTA negatif. Tuberkulosis merupakan salah satu penyakit dari 10 penyebab kematian di dunia. TBC juga merupakan penyebab utama kematian yang berkaitan dengan antimicrobial resentence dan pembunuh utama penderita HIV. Secara geografis sebagian besar insiden tuberkulosis pada tahun 2018 terjadi di Kawasan Asia Timur (44\%), Afrika (24\%) dan Pasifik Barat (18\%) (2).

Indonesia menempati rangking kedua dengan jumlah kasus TBC terbanyak didunia. Pada tahun 2016 di Indonesia jumlah kasus TBC sebanyak 360.565 kemudian meningkat pada tahun 2017 ditemukan jumlah kasus tuberkulosis sebanyak 425.089 kasus, pada tahun 2018 terdapat jumlah kasus tuberkulosis dengan semua tipe yaitu sebanyak 566.623 kasus dan pada tahun 2019 jumlah kasus tuberkulosis yang ditemukan sebanyak 543.874 kasus, sedangkan untuk angka kesembuhan TBC pada tahun 2019 hanya mencapai 170.179 (73,02\%). Angka kesembuhan ini belum mencapai target yang telah ditetapkan yaitu 85\%. Rendahnya angka kesembuhan berkaitan dengan waktu pengobatan yang cenderung lama dan mengakibatkan terjadi kebosanan atau ketidakteraturan berobat, sehingga mempengaruhi kesembuhan pasien TBC paru BTA positif, untuk mengatasi hal tersebut maka diperlukan Pengawas Menelan Obat (PMO) yang dapat bersikap tegas untuk mengawasi pasien dalam meminum obat (3)

Berdasarkan data yang diperoleh dari Dinas Kesehatan Provinsi Sulawesi Tengah, angka penemuan kasus tuberkulosis pada tahun 2019 yaitu 5.747 (52,07\%), namun hal ini belum memenuhi target angka penemuan kasus yaitu 80\%. Kabupaten/Kota yang telah mencapai target penemuan kasus TBC yaitu Banggai sebanyak 1.105 (89,8\%) kasus dan Morowali 452 (117\%) kasus. Angka kesembuhan pengobatan TBC di Sulawesi Tengah pada tahun 2015 sebesar 79,81\%, pada tahun 2016 sebesar 79\%, pada tahun 2017 sebesar 75\%, pada tahun 2018 sebesar 72\% dan pada tahun 2019 73,2\%. Dengan demikian Sulawesi Tengah belum mencapai standar $>85$, beberapa kendala yang dihadapi yaitu keberhasilan pengobatan pada beberapa rumah sakit di Kab/Kota masih rendah karena kasus pindah tidak ada keterangan baik hasil evaluasi pengobatan serta follow up kemajuan pengobatan dengan pemeriksaan sputum belum dilakukan sesuai protap pada beberapa fasyankes, serta masa pengobatan yang lama membuat pasien jenuh, adanya efek samping obat sehingga pasien menghentikan pengobatan secara sepihak (4). 
Berdasarkan data yang diperoleh dari Dinas Kesehatan Kota Palu, jumlah kasus TBC di Kota Palu mengalami Trend Fluktuatif yaitu pada tahun 2015 sebanyak 866 kasus, pada tahun 2016 mengalami penurunan menjadi 836 kasus dan meningkat pada tahun 2017 menjadi 908 kasus kemudian mengalami penurunan kembali pada tahun 2018 menjadi 557

kasus, pada tahun 2019 jumlah kasus TBC meningkat menjadi 642 kasus dan pada tahun 2020 mengalami penurunan menjadi 556 kasus (5)'

Kecamatan Palu Selatan merupakan salah satu Kecamatan di Kota Palu yang menyumbang angka kejadian Tuberkulosis yang cukup tinggi. Wilayah Kecamatan Palu Selatan terdiri dari 3 Puskesmas yaitu Puskesmas Mabelopura, Puskesmas Birobuli dan Puskesmas Bulili. Puskesmas Mabelopura merupakan salah satu daerah endemik pada kasus TBC di Kota Palu terdapat 62 kasus TBC yang berobat pada tahun 2019, pada Puskesmas Birobuli terdapat jumlah kasus TBC sebanyak 46 kasus dan pada Puskesmas Bulili terdapat 28 kasus. Berdasarkan data Tahun 2019, angka kesembuhan TBC yang ada di Kecamatan Palu Selatan didapatkan bahwa di Puskesmas Mabelopura mencapai 44 atau 70,96\%, Puskesmas Birobuli mencapai 30 atau 65,21\% dan Puskesmas Bulili mencapai 19 atau 67,85\%. Angka kesembuhan pada masing-masing Puskesmas belum mencapai target dikarenakan ketidakpatuhan pasien dalam pengobatan, pasien kurang mendapat pengawasan dari PMO dan adanya efek samping obat (5).

Salah satu kunci dalam keberhasilan pengobatan TBC yaitu kepatuhan pasien. Penderita TBC yang tidak patuh dalam pengobatan kemungkinan besar disebabkan oleh efek samping yang mungkin timbul, dan kurangnya peran pengawas menelan obat. Apabila dibiarkan dampak yang akan muncul jika pasien TBC berhenti minum obat adalah muculnya kuman tuberkulosis yang resisten terhadap obat, yang mengakibatkan pengendalian obat tuberkulosis akan semakin sulit dilaksanakan dan meningkatnya angka kematian akibat penyakit tuberculosis (6).

Indikator yang digunakan sebagai evaluasi pengobatan tuberkulosis yaitu angka keberhasilan pengobatan (success rate). Angka keberhasilan pengobatan ini dibentuk dari angka kesembuhan (cure rate) dan angka pengobatan lengkap. Menurut Permenkes RI No.67 Tahun 2016 di Indonesia data angka kesembuhan semua kasus TBC yang harus dicapai minimal 85\% sedangkan angka keberhasilan pengobatan semua kasus minimal 90\% (7).

Menghindari ketidakpatuhan dalam pengobatan Tuberkulosis maka diperlukan Pengawas Menelan Obat (PMO) yang bertugas untuk mendampingi pasien dalam menjalani pengobatan. Pasien yang berobat di Kecamatan Palu Selatan yang terdiri dari 3 Puskesmas 
yaitu Puskesmas Mabelopura, Puskesmas Birobuli dan Puskesmas Bulili masing-masing memiliki PMO yang selalu mengingatkan untuk melalukan kunjungan berobat ke Puskesmas dan meminum obat secara teratur. Tetapi dukungan dan motivasi yang diberikan PMO masih

kurang diberikan sehingga pasien menunda dan akhirnya lupa meminum obat. Menurut penelitian Prabowo (2014) menyatakan bahwa terdapat hubungan antara peran PMO terhadap kepatuhan kunjungan berobat pasien Tuberkulosis di Puskesmas Nogosari Boyolali (9), dan hasil penelitian Jumaelah (2013) menyatakan bahwa terdapat hubungan yang signifikan antara keteraturan pengobatan dengan status kesembuhan pasien Tuberkulosis, dengan adanya PMO dapat meningkatkan tingkat kesembuhan pasien TBC karena PMO bertugas untuk mengingatkan pasien TBC melalukan kunjungan berobat ke Puskesmas dan meminum obat secara teratur (10).

Efek samping dari OAT terbagi menjadi dua yaitu efek samping ringan dan efek samping berat. Efek samping yang dirasakan pasien TBC pada Puskesmas Mabelopura, Puskesmas Birobuli dan Puskesmas Bulili rata-rata memiliki efek samping yang sama yaitu efek samping ringan: tidak ada nafsu makan, mual dan efek samping berat: sakit perut, kemerahan pada air seni, nyeri sendi, demam menggigil dan rasa gatal pada kulit. Efek samping OAT lebih banyak terjadi di minggu pertama dan kedua pengobatan, sehingga di awal pengobatan penderita sudah mulai bosan dan merasa sia-sia melakukan pengobatan karena bukannya sembuh namun semakin bertambah penyakitnya. Menurut penelitian Nugroho (2017) menyatakan bahwa OAT memiliki efek samping yang dapat dirasakan oleh pasien TBC, efek samping dari OAT lebih banyak terjadi pada awal pengobatan sehingga pasien berhenti berobat dan akibatnya pasien mengalami kekebalan terhadap OAT atau disebut Multi Drug Resistent (TBC MDR).

\section{METODE}

Penelitian ini merupakan penelitian kuantitatif dengan pendekatan survei analitik, dengan desain Cross Sectional.. Lokasi penelitian ini dilakukan di Kecamatan Palu Selatan yang terdiri dari 3 Puskesmas yaitu Puskesmas Mabelopura, Birobuli dan Bulili. Penelitian ini dimulai pada tanggal 10 September 2020 hingga 03 Februari 2021. Populasi dalam penelitian ini adalah pasien yang datang berobat dan sudah menyelesaikan pengobatan pada Periode TW 1 s.d TW 4 Tahun 2019 yang berjumlah 136 orang. Sampel dihitung menggunakan rumus Lemeshow didapatkan sampel sebanyak 97 orang. Teknik pengambilan sampel yaitu Proportionate Stratified Random Sampling dengan kriteria yaitu pasien TBC 
Paru yang telah menyelesaikan pengobatan dan bersedia menjadi responden. Analisis data yang digunakan uji statistik Regresi dengan derajat kepercayaan 95\% $a<(0,05)$.

\section{HASIL}

\section{Karakteristik Pasien Tuberkulosis}

Tabel 1.

Analisis Univariat Karakteristik Responden

\begin{tabular}{|c|c|c|}
\hline Kelompok Umur & Frequency & Percent (\%) \\
\hline 4-12 Tahun & 4 & 4,1 \\
\hline 13-21 Tahun & 10 & 10,3 \\
\hline 22-30 Tahun & 21 & 21,6 \\
\hline 31-39 Tahun & 13 & 13,4 \\
\hline 40-48 Tahun & 21 & 21,6 \\
\hline 49-57 Tahun & 18 & 18,6 \\
\hline 58-66 Tahun & 8 & 8,3 \\
\hline 67-75 Tahun & 2 & 2,1 \\
\hline Total & 97 & 100,0 \\
\hline Jenis Kelamin & Frequency & Percent (\%) \\
\hline Laki-laki & 55 & 56,7 \\
\hline Perempuan & 42 & 43,3 \\
\hline Total & 97 & 100,0 \\
\hline Pendidikan Terakhir & Frequency & Percent (\%) \\
\hline Tidak Sekolah & 6 & 6,2 \\
\hline SD & 10 & 10,3 \\
\hline SMP & 8 & 8,3 \\
\hline SMA & 33 & 34,0 \\
\hline Diploma/S1/S2 & 40 & 41,2 \\
\hline Total & 97 & 100,0 \\
\hline Pekerjaan & Frequency & Percent (\%) \\
\hline Tidak Bekerja & 16 & 16,5 \\
\hline Pelajar/Mahasiswa & 13 & 13,4 \\
\hline PNS & 15 & 15,5 \\
\hline Karyawan Swasta & 19 & 19,6 \\
\hline Ibu Rumah Tangga & 21 & 21,6 \\
\hline Pedagang & 9 & 9,3 \\
\hline Satpam & 2 & 2,1 \\
\hline Supir & 1 & 1,0 \\
\hline Bengkel & 1 & 1,0 \\
\hline Total & 97 & 100,0 \\
\hline
\end{tabular}

Tabel di atas menunjukkan bahwa dari 97 responden, distribusi responden menurut kelompok umur terbesar terdapat pada kelompok umur 22-30 dan 40-48 Tahun sebanyak 21 
responden $(21,6 \%)$ sedangkan distribusi responden terkecil terdapat pada kelompok umur 6775 Tahun sebanyak 2 responden (2,1\%). Distribusi responden berdasarkan jenis kelamin

yaitu laki-laki sebanyak 55 responden $(56,7 \%)$ sedangkan perempuan sebanyak 42 responden $(43,3 \%)$. Responden dengan tingkat pendidikan Diploma/S1/S2 yaitu sebanyak 40 responden (41,2\%), sedangkan berdasarkan pekerjaan, maka Sebagian besar adalah ibu rumah tangga yaitu 21 responden $(21,6 \%)$.

Pengaruh Peran PMO terhadap Angka Kesembuhan Pasien TBC

Tabel 2

Pengaruh Pengawas Menelan Obat terhadap Angka Kesembuhan TBC

\begin{tabular}{|c|c|c|c|c|c|c|c|c|}
\hline \multirow{3}{*}{$\begin{array}{c}\text { Pengawas } \\
\text { Menelan } \\
\text { Obat }\end{array}$} & \multicolumn{4}{|c|}{ Kesembuhan } & \multirow{3}{*}{ Total } & \multirow{3}{*}{$\begin{array}{c}\text { Std. } \\
\text { Error }\end{array}$} & \multirow{3}{*}{$\mathbf{T}_{\text {hitung }}$} & \multirow{3}{*}{ Sig. } \\
\hline & \multicolumn{2}{|c|}{ Sembuh } & \multicolumn{2}{|c|}{$\begin{array}{c}\text { Tidak } \\
\text { Sembuh }\end{array}$} & & & & \\
\hline & $\mathbf{n}$ & $\%$ & $\mathbf{n}$ & $\%$ & & & & \\
\hline \multirow{2}{*}{$\begin{array}{c}\text { Berperan } \\
\text { Baik } \\
\text { Kurang } \\
\text { Berperan }\end{array}$} & 83 & 95,4 & 0 & 0 & 83 & \multirow{2}{*}{0.122} & \multirow{2}{*}{2.622} & \multirow{2}{*}{0.010} \\
\hline & 4 & 4,6 & 10 & 100 & 14 & & & \\
\hline Total & 87 & 100 & 10 & 100 & 97 & & & \\
\hline
\end{tabular}

Tabel di atas menunjukan bahwa PMO yang berperan baik Sebanyak 83 responden $(95,4 \%)$ memiliki pengawas menelan obat yang berperan dan sembuh, sedangkan sebanyak 4 responden $(4,6 \%)$ memilki pengawas menelan obat yang kurang berperan baik dan sembuh, dengan nilai Sig, 0,010 $(\mathrm{Sig}<0,05)$.

Pengaruh Efek Samping Obat terhadap Angka Kesembuhan Pasien TBC

Tabel 3.

Pengaruh Efek Samping OAT terhadap Angka Kesembuhan TBC

\begin{tabular}{|c|c|c|c|c|c|c|c|c|}
\hline \multirow{3}{*}{$\begin{array}{c}\text { Efek } \\
\text { Samping }\end{array}$} & \multicolumn{4}{|c|}{ Kesembuhan } & \multirow{3}{*}{ Total } & \multirow{3}{*}{$\begin{array}{l}\text { Std. } \\
\text { Error }\end{array}$} & \multirow{3}{*}{$\mathbf{T}_{\text {hitung }}$} & \multirow{3}{*}{ Sig. } \\
\hline & \multicolumn{2}{|c|}{ Sembuh } & \multicolumn{2}{|c|}{$\begin{array}{c}\text { Tidak } \\
\text { Sembuh }\end{array}$} & & & & \\
\hline & $\mathbf{n}$ & $\%$ & $\mathbf{n}$ & $\%$ & & & & \\
\hline Ada Efek & 87 & 100 & 10 & 100 & 97 & & & \\
\hline $\begin{array}{c}\text { Tidak Ada } \\
\text { Efek }\end{array}$ & 0 & 0 & 0 & 0 & 0 & 0.089 & 4.679 & 0.000 \\
\hline Total & 87 & 100 & 10 & 100 & 97 & & & \\
\hline
\end{tabular}

Tabel di atas menunjukan bahwa Pasien yang mengalam efek samping ada 87 orang $(100 \%)$, dengan nilai Sig, 0,000 $(\operatorname{Sig}<0,05)$.

\section{PEMBAHASAN}

Pengaruh Pengawas Menelan Obat terhadap Angka Kesembuhan TBC

World Health Organization (WHO) telah merekomendasikan strategi Directly 
Observed Treatment, Shortcourse (DOTS) untuk pengendalian TBC sejak tahun 1995 dengan melibatkan Pengawas Menelan Obat (PMO). Peran PMO sangat penting terhadap kepatuhan dan keteraturan minum obat. Hal ini bertujuan untuk mencapai kesembuhan pasien, mencegah penularan, dan menghindari kasus resisten obat. Kolaborasi petugas kesehatan dengan keluarga yang ditunjuk untuk mendampingi pasien, juga faktor yang perlu di evaluasi untuk menentukan tingkat keberhasilannya (11).

Salah satu komponen DOTS adalah pengobatan panduan OAT jangka pandek dengan pengawasan langsung. Untuk menjamin keteraturan pengobatan diperlukan seorang PMO. Seseorang yang ditunjuk menjadi PMO harus sesorang yang dikenal, dipercaya, dan disetujui baik oleh petugas kesehatan maupun pasien, selain itu harus disegani, dihormati oleh pasien serta yang tinggal dekat dengan pasien. Peranan PMO sangat mempengaruhi kedisiplinan pasien TB paru dan keberhasilan pengobatan. Pada saat seseorang dikatakan menderita TBC berdasarkan hasil diagnosis BTA, penderita TBC membutuhkan waktu yang cukup lama untuk menjalani pengobatan. Sejak Tahun 1995, WHO sudah merekomendasikan penerapan strategi DOTS yang bertujuan untuk mencegah penularan kuman TBC dan mencegah terjadinya Multi Drug Resistent-TB (MDR-TB). Apabila penularan kuman dapat dicegah maka insidensi TBC dapat diturunkan. Salah satu strategi dari DOTS sendiri adalah penerapan panduan OAT jangka pendek dengan pengawasan dari PMO (12).

Berdasarkan hasil penelitian yang dilakukan, menunjukan bahwa responden yang memiliki pengawas menelan obat (PMO) yang berperan baik sebanyak $83(85,6 \%)$ responden, sedangkan responden memiliki pengawas menelan obat yang kurang berperan baik sebanyak $14(14,4 \%)$ responden. Hal ini berdasarkan pernyataan responden bahwa ada $86(83,4 \%)$ responden memiliki pengawas menelan obat (PMO) yang memberikan motivasi dan mendorong pasien untuk tetap menelan obat secara teratur, $84(81,4 \%)$ responden menyatakan bahwa pengawas menelan obat menjelaskan manfaat pengobatan secara teratur, $82(79,5 \%)$ responden yang memiliki pengawas menelan obat yang mendengarkan keluhan anda mengenai pengobatan $\mathrm{TBC}$ serta $74(71,7 \%)$ responden yang memiliki pengawas menelan obat yang mengingatkan pasien waktu pemeriksaan dahak, 32 (31\%) responden memiliki pengawas menelan obat yang tidak membuat kesepakatan mengenai lokasi dan waktu menelan obat, $41(39,7 \%)$ responden memiliki pengawas menelan obat yang tidak menjelaskan tahapan pengobatan TBC pada keluarga pasien serta 48 (46,5\%) responden memiliki pengawas menelan obat yang tidak turut menemani pasien untuk mengambil OAT.

Berdasarkan hasil analisis korelasi pengawas menelan obat (PMO) sebesar 2,622 
dengan nilai sig dari pengawas menelan obat sebesar 0,010 dengan kriteria signifikan 0,05 . Nilai sig. pengawas menelan obat yaitu $0,010<$ dari kriteria signifikan yaitu 0,05 . Hal ini berarti variabel pengawas menelan obat berpengaruh signifikan terhadap variabel kesembuhan pada pasien TBC di Puskesmas yang berada di Kecamatan Palu Selatan. Hasil penelitian ini juga menunjukkan bahwa dari 83 responden yang memiliki pengawas menelan obat yang berperan baik, terdapat $83(95,4 \%)$ responden yang sembuh dan $0(0 \%)$ responden yang tidak sembuh, sedangkan dari 14 responden yang memiliki pengawas menelan obat yang kurang berperan baik terdapat $4(4,6 \%)$ responden yang sembuh dan 10 (100\%) responden yang tidak sembuh. Hasil penelitian menunjukkan bahwa pada saat PMO berperan dengan baik dalam mengawasi pasien TBC untuk menelan obat, akan membantu pasien untuk dapat sembuh dari penyakit TBC yang dideritanya. PMO yang berperan dengan baik akan dapat menjamin bahwa pasien TBC akan rutin untuk menelan Obat TBC sampai 6 bulan sesuai dengan proses pengobatan. Oleh sebab itu, selama masa pengobatan diperlukan kerja sama yang baik antara PMO dengan pasien dalam mematuhi peraturan tata cara minum obat dan kontrol kesehatan.

Aspek yang dapat menjadikan PMO mempunyai arti penting untuk pasien TBC adalah dukungan. Dukungan yang kuat dari PMO akan sangat membantu proses penyembuhan penyakit TBC misalnya dalam meningkatkan kepatuhan pengobatan dengan cara pengawasan dalam menelan obat serta memberi semangat kepada pasien. Dukungan emosional PMO pada pasien TBC sangat dibutuhkan karena tugas PMO adalah memberikan dorongan kepada pasien agar mau berobat secara teratur dan mengingatkan pasien untuk periksa ulang dahak pada waktu yang ditentukan. Dengan kinerja PMO yang baik, pasien lebih termotivasi untuk menjalani pengobatan secara teratur (12).

Hasil Penelitian ini sejalan dengan penelitian Ai, et al, tahun 2018, yang menunjukkan bahwa ada pengaruh PMO (DOT supervisor) dengan kesembuhan pasien TBC ( $p$ value < 0,01). Pasien yang diawasi oleh PMO dari keluarga, tingkat kesembuhannya sampai $80,1 \%$, sedangkan pasien yang PMO nya tidak berasal dari keluarga tingkat kesembuhannya mencapai 88,3\%. Hasil penelitian juga menyarankan agar pengawasan DOTS di daerah terpencil dapat dilakukan oleh keluarga yang sebelumnya sudah diberikan pelatihan untuk memastikan pengawasan pasien TBC untuk mengkonsumsi obat secara teratur (13).

Penelitian ini juga sejalan dengan penelitian Efri Yeni Tahun 2020 yang menunjukkan bahwa persentase responden yang gagal dalam pengobatan tuberkulosis lebih tinggi pada responden dengan kinerja pengawas minum obat yang tidak baik yaitu 35,3\% 
dibandingkan dengan yang kinerja pengawas minum obatnya baik yaitu 2,3\%. Hasil uji statistik diperoleh nilai $\mathrm{p}=0,001$ ( $p$ value $<0,05)$, yang berarti ada hubungan yang signifikan antara kinerja pengawas minum obat dengan kesembuhan pengobatan pada pasien TB Paru (14).

Penelitian ini sejalan dengan penelitian Napitupulu dan Harapah Tahun 2020 yang menunjukkan bahwa keberhasilan pengobatan TBC didukung oleh peran PMO yang mendukung pada responden sebanyak 28 orang $(70 \%) \%$, sedangkan dalam pengobatan TBC tidak didukung oleh peran PMO tetapi berhasil sebanyak 4 orang (10\%), pengobatan TBC tidak didukung oleh peran PMO yang tidak berhasil sebanyak 8 orang (20\%). Hasil uji analisis dengan menggunakan uji Fisher peran PMO terhadap keberhasilan pengobatan TBC di Puskesmas Ulak Tano didapatkan nilai P-Value 0,000, artinya terdapat hubungan yang signifikan antara peran PMO terhadap keberhasilan pengobatan TBC di Puskesmas Ulak Tano (15).

Hasil penelitian ini juga sejalan dengan penelitian (Agyeman and Ofori-asensoi, 2017) yang menunjukkan bahwa hasil uji Chi Square diperoleh nilai $\chi^{2}$ hitung sebesar 9,717 dengan tingkat signifikansi $p$-value sebesar 0,002. Keputusan uji adalah H0 ditolak karena nilai $p$ value lebih kecil dari $0,05(0,002<0,05)$, sehingga disimpulkan terdapat pengaruh peranan PMO terhadap keberhasilan pengobatan penderita TB Paru di wilayah kerja Puskesmas Baki Sukoharjo. Kecenderungan semakin baik peran PMO maka keberhasilan pengobatan semakin meningkat dan sebaliknya jika semakin buruk peran PMO maka keberhasilan pengobatan semakin kecil (17).

\section{Pengaruh Efek Samping OAT terhadap Angka Kesembuhan TBC}

Efek samping obat/adverse drug reaction (ADR) adalah respons terhadap suatu obat yang merugikan dan tidak diinginkan yang terjadi pada dosis yang biasanya digunakan pada manusia untuk pencegahan, diagnosis atau terapi penyakit atau untuk modifikasi fungsi fisiologik. Ditandai dengan adanya efek samping obat ringan dan efek samping obat berat. Efek samping obat ringan ditandai dengan gejala salah satu atau lebih dari satu gejala seperti tidak nafsu makan, mual, sakit perut, nyeri sendi, kesemutan dan rasa terbakar di kaki dan warna kemerahan pada air seni, flu sindrom (demam, menggigil, lemas dan sakit kepala dan nyeri tulang). Gejala efek samping obat berat ditandai dengan salah satu atau lebih dari satu gejala seperti gatal dan kemerahan pada kulit, gangguan pendengaran keseimbangan, tanpa

penyebab lain, bingung, mual muntah, gangguan penglihatan, syok, gagal ginjal akut dan penurunan produksi urin (18). 
Morbiditas dan mortalitas akibat tuberkulosis merupakan permasalahan yang sangat serius terutama akibat permasalahan timbulnya efek samping akibat penggunaan Obat Anti Tuberkulosis (OAT). Putusnya terapi akibat timbul efek samping menimbulkan 3 resistensi kuman sehingga memperberat beban penyakit dan beban pasien itu sendiri. Untuk mendapatkan hasil pengobatan yang tepat perlu adanya pemantauan efek samping obat, semua pasien TBC yang berobat seharusnya diberitahukan tentang adanya efek samping obat anti tuberkulosis, ini sangat penting untuk dilakukan agar pasien tidak salah paham yang bisa menimbulkan putus obat. Sebagian besar pasien merasa tidak tahan terhadap efek samping OAT yang dialami selama pengobatan. Beratnya efek samping yang dialami tersebut akan berdampak pada kepatuhan berobat pasien dan bahkan dapat berakibat putus berobat (loss to follow-up) dari pengobatan (19).

Berdasarkan hasil penelitian, menunjukan bahwa distribusi responden berdasarkan efek samping obat antituberkulosis (OAT) yaitu semua responden mengalami efek samping. Hal ini berdasarkan pernyataan responden bahwa terdapat $84(86,6 \%)$ responden yang merasa mual, $70(72,2 \%)$ responden yang mengalami hilang nafsu makan, $55(56,7 \%)$ responden yang merasakan nyeri sendi, $52(53,6 \%)$ responden yang merasakan nyeri perut, $49(50,5 \%)$ yang merasakan kesemutan, 43 (44,3\%) responden yang merasakan kemerahan pada air seni, $12(12,4 \%)$ responden yang merasakan kemerahan dan rasa gatal pada kulit, $9(9,3 \%)$ responden yang merasakan gangguan pendengaran dan keseimbangan, 7 (7,2\%) responden yang merasakan syok. Efek samping obat antituberkulosis umumnya terjadi pada bulan pertama dan kedua pengobatan (tahap intensif). Pada tahap ini, pasien sangat rentan mengalami efek samping obat dikarenakan obat antituberkulosis membutuhkan waktu penyesuaian dalam tubuh.

Berdasarkan hasil analisis korelasi efek samping OAT sebesar 4,679 dengan nilai sig dari efek samping OAT sebesar 0,000 dengan kriteria signifikan 0,05. Nilai sig efek samping OAT yaitu $0,000<$ dari kriteria signifikan yaitu 0,05 . Hal ini berarti variabel efek samping OAT berpengaruh signifikan terhadap variabel kesembuhan pada pasien TBC di Puskesmas yang berada di Kecamatan Palu Selatan. Hasil penelitian ini juga menunjukan bahwa dari 97 responden yang mengalami efek samping, terdapat 87 (100\%) responden yang sembuh dan $10(100 \%)$ responden yang tidak sembuh. Mayoritas responden yang sembuh, mengalami

efek samping yang tidak mengganggu pengobatan sedangkan responden yang tidak sembuh mengalami efek samping yang mengganggu pengobatan, responden tidak tahan 
dengan efek samping yang dirasakan selama pengobatan sehingga responden memberhentikan pengobatannya.

Upaya yang dilakukan apabila pasien mengalami efek samping yaitu petugas kesehatan biasanya mengkonsultasikan efek samping yang dirasakan oleh pasien dengan dokter umum yang ada di puskesmas dan pasien diberikan obat tambahan sesuai dengan efek samping yang dirasakan. Selain itu, pasien harus memiliki gaya hidup yang baik seperti rutin melakukan olahraga serta mengkonsumsi makanan dan minuman yang sehat agar tidak memicu timbulnya efek samping. Efek samping penyakit TBC dan pengobatan dapat dinyatakan sebagai efek samping yang multisistem dengan berjalan proses perawatan dan pengobatan terjadi perubahan nafsu makan, adanya alergi gatal-gatal dan nyeri serta perubahan warna urin saat mengkonsumsi obat. Efek samping yang berdampak pada multisystem yang berdasarkan adanya sub kategori gangguan rasa nyaman, peningkatan nafsu makan, perubahan warna urin dan gangguan sirkulasi ekstrimitas (20).

Hasil penelitian ini sejalan dengan penelitian Seniantara, dkk., Tahun 2018 menunjukkan bahwa seluruh pasien TBC yang menjadi responden (100\%) mengalami efek samping dari konsumsi OAT. Efek samping yang dialami diantaranya: jantung berdebardebar, gangguan penglihatan, muntah, gatal pada kulit, gangguan keseimbangan, air seni berwarna, gangguan pendengaran, tidak nafsu makan, nyeri sendi, kesemutan. Hal dapat berdampak pada tingkat kepatuhan penderita dalam mengkonsumsi OAT, padahal kepatuhan dalam minum OAT sangat berperan penting dalam proses penyembuhan penyakit tuberkulosis. Hasil analisis statistik antara pengaruh efek samping OAT terhadap kepatuhan minum obat pada pasien TBC dengan menggunakan uji korelasi Spearman rank, diperoleh nilai $\rho$ value $=0,000<\alpha 0,05$ yang artinya Ha diterima, artinya ada hubungan yang signifikan antara pengaruh efek samping OAT terhadap kepatuhan minum obat pada pasien $\operatorname{TBC}(21)$.

Hasil penelitian ini sejalan dengan penelitian Merzistya dan Rahayu Tahun 2019 menunjukkan bahwa ada hubungan efek samping OAT terhadap kejadian putus berobat penderita TB Paru $(p$ value $=0,01<0,05)$. Hasil survei yang dilakukan peneliti, diketahui bahwa alasan pasien TB Paru memutuskan untuk menghentikan pengobatan salah satunya adalah efek samping yang diterima setelah mengkonsumsi OAT. Banyaknya pasien yang mengalami efek samping baik ringan maupun berat yang sering menjadikan pasien memutuskan untuk berhenti berobat dikarenakan takut apabila dilanjutkan akan semakin parah dan tidak tahan bila terus menerus dialami (22). 
Hasil penelitian ini sejalan dengan penelitian Kurane, Singh dan Waghmare Tahun 2014 menunjukkan bahwa variabel efek samping mempunyai hubungan yang bermakna ( $\mathrm{p}=$ 0,000) dengan kepatuhan penderita TB paru minum obat $(\mathrm{OR}=22,339$, 95\% CI: 2,076 240,343). Hal ini berarti penderita TBC yang memiliki efek samping ringan cenderung patuh sebesar 22.3 kali lebih banyak dibandingkan orang yang efek samping berat.

Hasil Penelitian ini tidak sejalan dengan penelitian Niviasari, Saraswati dan Martini Tahun 2015 yang menunjukkan bahwa hasil tabulasi silang didapatkan nilai $\mathrm{p}=0,636$ ( $p$ value > 0,05) H0 diterima yang berarti efek samping obat tidak berhubungan dengan status kesembuhan pasien tuberkulosis paru. Dalam penelitian ini, terdapat 48,5\% merasakan efek samping OAT yang berbeda-beda, seperti mual (57,6\%), nyeri sendi $(57,6 \%)$, kesemutan (18\%), gatal (18\%), gangguan pendengaran (18\%), tidak nafsu makan (9\%) dan sakit perut (3\%). Ada maupun tidak ada efek samping OAT tidak akan berpengaruh terhadap sembuh maupun tidak sembuhnya pasien tuberculosis (20).

\section{KESIMPULAN DAN SARAN}

Terdapat pengaruh yang signifikan antara pengawas menelan obat $(0,010)$ dan efek samping OAT $(0,000)$ terhadap Angka Kesembuhan (Cure Rate) Pasien Tuberkulosis di Kecamatan Palu Selatan.

Diharapkan untuk Pengawas Menelan Obat lebih meningkatkan lagi kinerjanya dalam mengawasi langsung pasien TBC seperti turut menemani pasien untuk mengambil OAT, menjelaskan tahapan pengobatan TBC pada keluarga pasien dan membuat kesepakatan mengenai lokasi dan waktu menelan obat. Melakukan tatalaksana efek samping seperti memberikan terapi obat tambahan sesuai dengan gejala yang timbul. Dan juga diharapkan kepada pasien TBC agar tetap patuh dalam menjalani pengobatan agar kesembuhan dapat dicapai sesuai dengan yang diharapkan dan bagi keluarga sebaiknya tetap memberikan dukungan pada pasien dengan cara selalu mengingatkan dan memotivasi pasien untuk mengonsumsi obat secara teratur.

\section{DAFTAR PUSTAKA}

1. Kemenkes. Infodatin Pusat Data dan Informasi Kementerian Kesehatan RI. 2018;

2. (WHO) WHO. Global Tuberculosis Report 2019.

3. Kemenkes. Infodatin Pusat Data dan Informasi Kementerian Kesehatan RI. Jakarta; 2019.

4. Dinas Kesehatan Provinsi Sulawesi Tengah. Profil Penyakit menular Tuberculosis. 2019.

5. Dinas Kesehatan Kota Palu. Profil Penyakit Menular Tuberculosis. 2019;

6. Nazilatul Fadlilah. Hubungan Karakteristik Pengawas Menelan Obat terhadap Kepatuhan Berobat Pasien Tuberkulosis di Puskesmas Pragaan Tahun 2016. J Berk Epidemiol. 
2017;5(3):1-13.

7. Kemenkes. Permenkes Nomor 67 Tahun 2016 tentang Penanggulangan Tuberculosis. 2016;

8. Sri S. Purwaningsih \& Widayatun. PERKEMBANGAN HIV DAN AIDS DI INDONESIA: Tinjauan Sosio Demografis. J Kependud Indones. 2008;3(2):75-95.

9. Prabowo RDR. Hubungan antara Peran Pengawas Minum Obat (PMO) dengan Kepatuhan Kunjungan Berobat pada Pasien Tuberculosis Paru (TB Paru) di Puskesmas Nogosari Boyolali. Univ Muhamadiyah Surakarta [Internet]. 2014;1-12. Available from: eprints.ums.ac.id/38799/23/02. Naskah Publikasi.pdf

10. Nurhayati J. Hubungan Kinerja Pengawas Menelan Obat terhadap Keberhasilan Pengobatan TB Paru dengan DOTS di RSUP Dr. Kariadi Semarang. Medica Hosp J Clin Med. 2014;2(1):54-7.

11. Utami NA, Tunru ISA, Yusnita Y. Hubungan Tingkat Pengetahuan Terhadap Keberhasilan Pengobatan Tuberkulosis di Puskesmas Kecamatan Johar Baru Jakarta Pusat Tahun 2016. J Profesi Med J Kedokt dan Kesehat. 2018;12(2):13-7.

12. Tindatu HF, Maramis FR., Wowor R. Analisis Peran Pengawas Menelan Obat Dalam Kesembuhan Pasien Tb Di Puskesmas Bitung Barat Kota Bitung Tahun 2020. Kesmas. 2020;9(7):128-36.

13. Ai X, Men K, Guo L, Zhang T, Zhao Y, Sun X, et al. Factors associated with low cure rate of tuberculosis in remote poor areas of Shaanxi Province, China: A case control study. BMC Public Health. 2010;10.

14. Yeni E. Analisis Faktor-Faktor Yang Berhubungan Dengan Tuberkulosis Paru. J Hum care. 2020;5(1):304-10.

15. Napitupulu M, Harahap LF. Hubungan peran pengawas menelan obat (PMO) dengan keberhasilan minum obat pasien Tuberkulosis paru Di wilayah kerja puskesmas Ulak Tano. J Komunitas Kesehat Masy [Internet]. 2020;2(1):41-7. Available from: https://uit.e-journal.id/JKKM/article/view/750

16. Wahyuningrum MT. Hubungan Kepatuhan Minum Obat Anti Tuberkulosis (Oat) Dengan Status Gizi Pasien Tbc Paru Fase Intensif Di Bbkpm Surakarta. 2018;

17. Agyeman AA, Ofori-Asenso R. Tuberculosis-an overview. J Public Heal Emerg. 2017;1(3):7-7.

18. Harahap RA. Pengaruh Faktor Predisposing, Enabling Dan Reinforcing Terhadap Pemberian Imunisasi Hepatitis B Pada Bayi Di Puskesmas Bagan Batu Kecamatan Bagan Sinembah Kabupaten Rokan Hilir. Jumantik. 2016;1(1):79-103.

19. Sari ID, Yuniar Y, Syaripuddin M. Studi Monitoring Efek Samping Obat Antituberkulosis Fdc Kategori 1 Di Provinsi Banten Dan Provinsi Jawa Barat. Media Penelit dan Pengemb Kesehat. 2014;24(1):28-35.

20. Niviasari DN, Saraswati LD, Martini. Faktor-Faktor Yang Berhubungan Dengan Status Kesembuhan Penderita Tuberkulosis Paru. J Kesehat Masy. 2016;3(3):141-51.

21. Kadek S, Theresia I, Gabrilinda AY. Pengaruh Efek Samping Oat (Obat Anti Tuberculosis) Terhadap Kepatuhan Minum Obat Pada Pasien Tbc Di Puskesmas. iJurnal Keperawatan Suaka Insa. 2018;3(2):1-12.

22. Merzistya ANA, Rahayu SR. Kejadian Putus Berobat Penderita Tuberkulosis Paru. Higeia J Public Heal Res Dev. 2019;2(3):298-310. 